\title{
Yitirdiklerimiz
}

\section{DOÇ. DR. SEYITTNAZAR ARNAZAROV (1952 - 2020)}

\author{
Berdi SARIYEV* \\ Maral TAGANOVA** \\ Gülnara KOLATOWA***
}

Seyitnazar Arnazarov, Türkmenistan Bilimler Akademisi yanında yer alan Mahtumkulu Dil ve Edebiyat Enstitüsünde yıllarca birlikte çalıştığım meslektaşım ve azimli bir iş arkadaşımdı.

İşten eve birlikte dönerdik, çünkü Aşgabat’ta ikamet ettiğimiz yerler de birbirine yakındi.

Seyitnazar Arnazarov; Devletmehmet Azadi Türkmen Millî Dünya Dilleri Enstitüsünde birlikte çalıştığım iş arkadaşım! Aynı bölümde çalıştık, Türkmen dili üzerine dersler verdik.

Seyitnazar Arnazarov ile Türkmenistan'dan yurt dişına (dost ve kardeş Türkiye Devleti'ne) çalışmak üzere birlikte aynı uçakta seyahat ettik. Beraberce Ankara'ya geldik ve hep birlikte hareket ettik. İkimiz de Eryaman'a yerleştik. Dil projesinde birlikte çalıştık.

1997 yılında çalıştı̆̆ımız üniversiteler açısından ayrıldık. O Gazi Üniversitesinde işe başladı; ben de Ankara Üniversitesinde işe başladım. Ancak Eryaman'da komşu olarak yaşıyorduk.

Geliș Tarihi/ Date Applied: 25.08 .2020

Kabul Tarihi/ Date Accepted: 4.09.2020

Makalenin Künyesi: Sarıyev, B., Taganova, M. ve Kolatowa, G. (2020). "Doç. Dr. Seyitnazar Arnazarov(1952 - 2020)". Türk Dünyası Dil ve Edebiyat Dergisi, 50, 377-384.

DOI: $10.24155 /$ tdk.2020.154

Doç. Dr., Ankara Üniversitesi, Dil ve Tarih-Coğrafya Fakültesi, Çağdaş Türk Lehçeleri ve Edebiyatları Bölümü Öğretim Üyesi, berdisariyev@gmail.com

** Doç. Dr., Türkmenistan Bilimler Akademisi, Mahtumkulu Dil, Edebiyat ve Milli Yazmalar Enstitüsü, Çağdaş Türkmen Dili ve Tarihi Bölümü Baş Uzmanı. Aşkabat-Türkmenistan. manyeje@mail.ru

**** TYA-nyň Magtymguly adyndaky dil, edebiýat we milli golýazmalar institutyny. Așkabat-Türkmenistan [Türkmenistan Milli İlimler Akademisi, Mahtumkulu Dil ve Edebiyat Enstitüsü] gulnarkalatova20@ gmail.com 
Pek çok toplantı, konferans ve etkinliklere birlikte katıldık. Birlikte konuştuk, birlikte dertleştik, birlikte tartıştık, birlikte barıştık...

O, tabiatı gereği yumuşak huyluydu. Güleç yüzlü, uyumlu ve zarif bir kişiliğe sahipti. Komşu olarak, arkadaş olarak, meslektaş olarak, onun yüksek sesle konuştuğunu, yüksek sesle bağırdığını asla duymadım.

Çok kitap okurdu. Bana, onun ilk dostunu söyle veya göster deseler; "kitap" diye cevap verirdim ve kitabı gösterirdim. Gerçekten tam bir kitap kurduydu... Onda olmayan kitap yoktu, evin içinde kütüphane var desem abartmış olmam.

Kuşları pek severdi, hatta evinde de kuş beslerdi. Birlikte yürüdüğümüzde, bir kuş sesi duydu mu hemen seni durdurur, "İ̧sittin değil mi deminki sesi, çok hoş sestir, filan kuşun sesi” diye belirtirdi.

Aşırı derecede futbol aşığıydı. Rus ve dünya futbolundan bahsedildi mi, kendini tutamaz ve mutlaka muhabbete dâhil olurdu. Oyuncuları ad ve soyadlarıyla tanırdı. Türkiye'de çalıştı̆̆ dönemde de Türk futbolunun hayraniydi.

Seyitnazar Arnazarov, Gazi Üniversitesinde birlikte çalıştığı iş arkadaşlarının hepsini dost bilirdi ve daima saygı gösterirdi. Bununla beraber onun dilinden düşürmediği bir dostu vardı. O da merhum Himmet Biray'd1. İkisi de birbirlerine derin saygı gösterirlerdi. Birlikte çalışırlar, hatta aile olarak birbirlerini ziyaret ederlerdi.

Seyitnazar'ın hayat hikâyesi ve yaptığı çalışmalar hususunda da kısaca şunları söyleyebiliriz: O hakikaten çok çalışkandı, ömrünü işine adamış bir âlimdi. İş denildiğinde; yorulma, mazeret nedir bilmezdi.

Seyitnazar Arnazarov, 1952 yılında Türkmenistan'ın Ahal vilayetine bağlı Bäherden ilçesinde dünyaya gelir. İlk ve ortaöğrenimini burada tamamladıktan sonra 1969'da Mahtumkulu Türkmen Devlet Üniversitesinin Türkmen Filolojisi Fakültesine başlar. 1974 yılında üniversiteden mezun olan Arnazarov, Türkmenistan Bilimler Akademisinin Mahtumkulu Dil ve Edebiyat Enstitüsünde önce asistan, sonra da uzman olarak 18 yıl çalışır. 1982'de "Türkmen Türkçesinde Nutuk Fiilleri" başlıklı tezini savunarak filoloji bilim dalında doktor olur. 1992 yılından itibaren doçent olarak Devletmemmet Azadi Türkmen Millî Dünya Dilleri Enstitüsünde ders vermeye başlar. 
“Ortak Türk Dili Yazı Projesi”ne katılmak üzere Türk Dil Kurumu ve Türk İşbirliği Kalkınma Ajansı (TİKA)'nın davetiyle 1994'te Türkiye’ye gelen Arnazarov, "Çağdaş Türk Lehçelerinin Karşılaştırmalı Grameri ve Sözlüğü” projesi kapsamında Türkmen Türkçesinin gramerini ve Türkmence sözlüğün bazı madde başlarını kaleme alır.

10 Aralık 1997 tarihinden itibaren Gazi Üniversitesi Fen Edebiyat Fakültesi Çağdaş Türk Lehçeleri ve Edebiyatları Bölümü'nde misafir öğretim üyesi olarak çalışmaya başlar. Arnazarov, Türkiye'de bulunduğu sürede birçok akademik çalışmaya imza atar. 2002 yılında TÜRKSAV tarafından “Türk Dünyası Hizmet Ödülüne”, 2004 y1lında ise Karaman Valiliği ve Türk Dil Kurumu tarafından “Türk Dili Ödülü”ne layık görülür.

Arnazarov evli ve altı çocuk sahibidir. Türkiye'de bulunduğu sırada pek çok kurultay, konferans ve sempozyuma iştirak edip bildiriler sunar. Türkmen Türkçesi ve Türkiye Türkçesi arasındaki yalancı eş değerlilik meselesi üzerinde birçok yazısı bulunan Arnazarov; Türkiye Türkçesinden Türkmen Türkçesine, Türkmen Türkçesinden de Türkiye Türkçesine birçok kitap ve makale aktarır. Bunlardan bazıları "Türkiye Türk Edebiyatı (Tarih-Adlar-Metinler), Türk Ocakları, Eğitim ve Kültür Vakfı, Ankara 2002"; Doç. Dr. Nergis Biray ile birlikte Türkmen Türkçesinden Türkiye Türkçesine aktarılmış olan "Soltanşa Atanıyazov, Şecere (Türkmenistan Soy Ăgacı), Ötüken, İstanbul 2010” gibi çalışmalardır.

Arnazarov ayrıca, Türkiye Diyanet İşleri Başkanlı̆̆ı'nın teklifiyle, Mehmet Soymen'in "Cep Ilmihali” (1996), Seyfettin Yazıcı'nın "Resimlerle Namaz” (1997), Lütfü Şentürk'ün “Íslam Dininde Haramlar ve Günahlar” (1998), A. Topaloğlu'nun "Ateizm ve Eleştirisi” (1999), Lütfi Şentürk'ün “Íslam Inanç Esasları Akaid” (2000), Mehmet Erdoğan'ın "Gençlerle Söyleşi” (2010) gibi birçok kitabı da Türkmen Türkçesine aktarır. Yine, Diyanet İşleri Başkanlığının yayımladığı Diyanet Avrasya dergisindeki makaleleri de Türkmen Türkçesine kazandırmıştır.

Ord. Prof. Dr. Muratgeldi Soyegov ile birlikte hazırladıkları Örnekli Türkmence Gramer (Türkmence Öğrenenler İçin) adlı çalışması, Prof. Dr. M. Fatih Kirişçioğlu ile Arş. Gör. Sümeyra Harmanda'nın editörlüğünde 2017 yılında Türkiye'de yayımlanmıştır. Bu kitapla ilgili olarak 2017 yılında Gazi Türkiyat dergisinin 21. sayısında Emrah Yılmaz tarafından bir tanıtım ve değerlendirme yazısı da yazılmıştır.

Seyitnazar Arnazarov, 2013 yılının Ekim ayından itibaren emekli olup Türkmenistan'a geri dönme kararı almıştır. Gazi Üniversitesindeki mesai arkadaşları aynı yıl Arnazarov'un makalelerini bir araya getiren bir kitap ("Seyitnazar Arnazarov Makaleler". Hazırlayanlar: Hüseyin Yıldırım, Veli Savaş Yelok, Tuğba Bayrakdarlar, Soncağ Yay. Ankara 2013) hazırlayarak 
meslektaşlarına ahde vefa örneği göstermişlerdir. Arnazarov'un makalelerinin topluca bir araya getirildiği bu eserde, ayrıca onun hayatı ve diğer eserlerinin bibliyografyası da verilerek Türklük bilimi araştırıcılarının istifadesine sunulmuştur.

Seyitnazar Arnazarov Türk Dil Kurumu tarafından yayınlanmakta olan Türk Dünyası Dil ve Edebiyat dergisinin de Yurt Dışı Temsilcilikler üyesidir.

Seyitnazar Arnazarov'un bilimsel çalışmalarına dair detaylı bilgiler Pamukkale Üniversitesi Fen-Edebiyat Fakültesi Çağdaş Türk Lehçeleri ve Edebiyatları Bölümü Dr. Öğrt. Üyesi Soner Sağlam tarafından hazırlanmış ve Türkiye Dışındaki Türk Dünyası Türkologları (Editör: Prof. Dr. Ahmet Buran) adlı eserin 1. cildinde Ankara'da 2019 yılında yayımlanmıştır. Bu eserde Arnazarov'un çalışmaları; kitaplar, makale ve tebliğler ve çeviriler başlı̆g 1 altında kronolojik olarak verilmiştir.

Ayrılık ile ilgili olarak başladığını bitirmek de zor imiş:

Bu ayrılık, evvela 2013 yılında Seyitnazar Arnazarov'un Türkmenistan'a temelli olarak dönmesiyle başlamıştı.

Nihai ayrılığın vakti ise; 23 Temmuz 2020, saat 07:00.

Hem uzaktan (Aşgabat'tan) hem de sabah erkenden gelen telefon sesi...

Şafak vaktinde gelen telefon sesinden kim ürpermez ki. Fakat yurt d1şında yaşayanlar için bu duygu; hissedilen ürpertinin iki, üç kat fazlasına tekabül ediyor... Evet, bu telefon sesi maalesef Seyitnazar'ın ebediyete intikal ettiği haberini ulaştırdı.

Ailesine, sevenlerine ve Türk bilim dünyasına baş sağlığı diliyorum.

\section{Ýatan yeriň yagty bolsun, Seýitnazar Mugallym!}

\section{Türkmen Diline Wepaly Hyzmat Eden Alym Seyitnazar ARNAZAROV}

Ömrüni türkmen dilini öwrenmäge bagyşlan alymlaryň içinde Seýitnazar Ärnazarowa aýratyn orun degişlidir. Bu alym diňe bir türkmen diline degişli ylmy işleri bilen tanalman, eýsem türkmen dilini Türkiýe Respublikasynyň Ankara şäherinde ýerleşýän Gazy uniwersitetinde okaýan diňe bir türklere däl, eýsem dünýäniň dürli ýurtlaryndan gelen talyplara türkmen dilinden ders berip, olaryn̆ gowy hünärmen bolup ýetişmeklerinde bahasyna ýetip bolmajak uly işleri bilen dünýä türkologiýasynda meşhurlyk gazandy. Onuň Türkmenistanda we Türkiýe Respublikasynda taýýarlan şägirtleriniň köpüsi özleriniň ylmy işlerini türkmen dilini öwrenmäge bagyşlap, alymlyk derejeleriniň eýesi boldular.

Türkmen Türkçesi ile yazılan bu bölüm Gülnara KOLATOWA'ya aittir. 
Alymyn̆ terjimehaly hakynda "Türkmen dilçileri" diýen kitapda we 2019-njy ýylda Türkiýede neşir edilen «Türk dünýäsi türkologlary» atly ensiklopediýadan hem giňden tanyşmak bolar.

Biz hem ýakynda biwagt aramyzdan giden Seýitnazar Ärnazarowy ýatlap, gazetiň okyjylaryny onuň ömri we döredijiligi bilen tanyşdyrmagy maksat edindik.

Alym Ahal welaýatynyň Bäherden etrabynyn̆ Sünçe obasynda 1952nji dünýä inýär. 1969-njy ýylda Bäherdende orta mekdebini üstünlikli tamamlap, şol ýyl Türkmen döwlet uniwersitetiniň türkmen filologiýasy fakultetine okuwa girýär we ony 1974-nji ýylda üstünlikli tamamlaýar. Şol 1974-nji ýylda-da Türkmenistanyň Ylymlar Akademiýasynyň Magtymguly adyndaky Dil we edebiýat institutynda zähmet ýoluna başlaýar. Oňa institutynyn̆ häzirki zaman türkmen dili bölüminde filologiýa ylymlarynyň kandidatlary B.Hojaýew, A.Borjakow, M.Soýegow dagy bilen işlemek nesip edýär. Seýitnazar ilki laborant, soň kiçi ylmy işgär we uly ylmy wezipelerinde on sekiz ýyl işledi. Şol döwürde ol «Türki dilleriň günorta-günbatar toparynda hyýal aňladýan işlik formalary» diýen işini ýerine ýetirýär.

1982-nji ýylda Seýitnazar «Türkmen dilinde sözleýiş işlikleri» diýen temadan üstünlikli kandidatlyk dissertasiýasyny goraýar. Şol işinde türkmen, türkiýe, azerbaýjan we gagauz dillerini deňeşdirýär. Bu işi üçin ol filologiýa ylymlarynyň kandidaty diýen alymlyk derejesine mynasyp bolýar. 1982-nji ýylda S. Ärnazarowyň bu işi «Türkmen dilinde sözleýiş işlikleri (deňeşdirme planda)» atly monografiýa görnüşinde neşir edilýär.

Ylmy işini pedagogik iş bilen üstünlikli utgaşdyrýar. Ol D.Azady adyndaky Türkmen milli Dünýa dilleriň institutynda dosent wezipesinde türkmen dilinden sapak berýär. Onlarça talyplaryn̆ türkmen dil bilimi ylmyna gelmegini gazanýar. Ol ýaşlara bilim bermegi jandan gowy görerdi, şol döwürdäki işdeşleriniň aýtmagyna görä, alym:"Her gezek talyplarym "Salam, mugallym!" diýip ýüzlenende, bir ýigdelýärin" diýip, ýürekden aýdan sözlerini ýatlaýarlar.

1994-nji ýylda Türkiýäniň Ankara şäherinde TIKA we Türk Dil Kurumynyn̆ "Şärikdeş türki dilleriniň ýazuw proýektine" dilçi alym hökmünde işe çagyrylýar. Ol türkmen diliniň grammatikasyna we sözlükleri barada birnäçe makalalary ýazyp tabşyrýar.

Soňra 1997-nji ýyldan başlap, Türkiýäniň Ankara şäherindäki Gazi uniwersitetde dosent wezipesinde işleýär.

S. Ärnazarow Türkiýede ýaşaýan wagty birnäçe ylmy işleri ýerine ýetirýär. Onuň çeken zähmeti üçin 2002-nji ýylda TÜRKSOÝ tarapyndan «Türk dünýasi hyzmat baýragyna», 2004-nji ýylda bolsa, karama 
wezipesine we Türk dili hyzmatdaşlygy (TIKA) tarapyndan «Türk dili baýragyna» mynasyp bolýar. Türkiýede köp sanly gurultaýlara, konferensiýalara we simpoziumlara gatnaşýar, türkmen diliniň inçe syrlaryny açyp görkezýän çykyşlar edýär we dilçi kärdeşleriniň gowy bahasyna mynasyp bolýar.

Seýitnazar terjimeçi hökmünde hem bellidir. Onuň terjimeleri arkaly türk dilli okyjylar Soltanşa Atanyýazowyn̆ "Şejere (Türkmenistanyn̆ Şejere daragty)" atly kitaby bilen 2010-njy ýylda tanyşdylar.

Kitabyn̆ türkmen muşdaklary üçin S. Ärnazarow Nihal Atsyzyň «Boz gurtlaryň ölümi» atly romanyny biziň ene dilimize terjime etdi. Mundan başga-da yslam dininiň aýratynlyklary düşündirýän kitaplary ençemesi hem alym tarapyndan terjime edilip neşir edildi (Mehmet Soýmeniň «Jübi ylmy haly» (1996), Seýfettin Ýazyjynyň «Suratlar bilen namaz» (1997), Lütfü Şentürkiň «Yslam dininde haramlar we günäler» (1998), A. Topaloguonyň «Ateizm we tankydy» (1999), Lütgü Şentürkiň «Yslam ynanjynyn̆ esaslary» (2000), Mehmet Erdoganyn̆ «Ýaşlar bilen Gürrüň » (2010), «Dini Awresýa» žurnalyndaky makalalar).

Dilçileriň arasynda S.Ärnazarowyň akademik, filologiýa ylymlarynyn̆ doktory Myratgeldi Söýegow bilen bilelikde taýýarlanan "Nusgaly türkmençe grammatikasy (Türkmençe öwrenýärler üçin)" atly Türkiýede çap edilen işleri uly abraýa eýe boldy.

Seýitnazar Ärnazarow 2013-nji ýylyň oktyabrynda dynç alyşa çykyp, Türkmenistana gaýdyp gelýär. Ol 2014-2015-nji ýyllarda Türkmenistanyň Ylymlar akademiýasynyn̆ "Ylym" neşirýatynda redaktor, soňra baş hünärmen wezipelerinde işleýär. 2015-nji ýylyn̆ aprelinden başlap, Türkmenistanyn̆ Ylymlar akademiýasynyň öňki Milli golýazmalar institutynyn̆ türkmen diliniň çeşmeleri bölüminde, soňra ömrüniň soňky günlerine çenli TYA-nyn̆ Magtymguly adyndaky Dil, edebiýat we milli golýazmalar institutynyn̆ häzirki zaman türkmen dili we taryhy bölüminde esasy ylmy işgär wezipesinde işledi. Ol gijesini gündiz edip zähmet çekip, orta asyrlaryn̆ beýik türkmen şahyry Hapyz Horezminiň "Diwanynyň” dil aýratynlygyna bagyşlanan ylmy işini ýazdy we institutda türkmen diliniň taryhyna degişli çapa taýýarlanan golýazma çeşmeleriniň hronologik yzygiderliligi boýunça görkezjini taýýarlady. Ol türkmen we türk dilleriniň umumylyklaryna bagyşlanan onlarça makalalaryny hem neşir etdirdi. Institutda işleýän ýaş ýigitlerdir-gyzlar üçin ýörite türkmen dilini çuňňur öwrenmek boýunça sapaklary gurnap, irmün-arman olar bilen ene dilimiziň kynçylyk döredip biläýjek meseleleriniň üstünde yzygiderli durup geçdi.

S. Ärnazarow 4 kitabyň, 50-ä golaý makalalaryň we 10 sany terjimäniň awtorydyr. Ol 50 ýyllap türkmen dil bilimine wepaly hyzmat edip, onun̆ 
20 ýylyny Türkiýede bolup, biziň ýurtlarynyzyn̆ arasyndaky dotluk-doganlyk gatnaşyklaryň ösmegine uly goşant goşdy.

Alym türkmen kärdeşleriniň ylmy makalalarynyň daşary ýurtlarda neşir edilmegine hem uly goldaw berdi. Mysal üçin, TYA-nyň Magtymguly adyndaky Dil, edebiýat we milli golýazmalar institutynyn̆ esasy ylmy işgäri, filologiýa ylymlarynyn̆ kandidaty M.Taganowanyn̆ "Mirasyn̆ çemenleri" atly okyjylaryň uly gyzyklanma bilen internetden okaýan, Türkmenistanda neşir edilen kitaplar baradaky synynyn̆ Türk dili kurumynyn̆ žurnalynda neşir edilmegi hut S.Ärnazarowyň tagallasynyň netijesidir. Şeýle-de şol institutyn̆ baş ylmy işgäri, filologiýa ylymlarynyň kandidaty Amanmuhammet Geldimyradowyn̆ türkmen dilindäki wariantlaşma bagyşlanan makalasynyn̆ Azerbaýjanda çap edilmeginde-de Seýitnazaryn̆ kömegi uludyr.

Türkiýede bilim beren şägirtleri hormatly halypalary Seýitnazaryn̆ türkmen dil bilimi boýunça ýazan işleriniň hemmesini bir ýere jemläp, olary türk diline terjime edip, ýörite kitap görnüşinde çapdan çykardylar. Bu bolsa olaryň öz halypalaryna goýýan hormatlarynyn̆ bimöçberdigini görkezýär.

Durmuş Seýitnazar Ärnazarowy özüniň agyr synaglaryna sezewar etdi, alym olardan mertlik bilen geçip, ömrüniň soňky pursatlaryna çenli özüniň kärine, kitaba, güllere we guşlara bolan söýgüsini öz gelni Sona bilen ýetişdiren alty çagasyna, agtyklaryna hem ýüzlerçe şägirtlerine miras goýmagy başardy.

Seýitnazar işe ýüregi bilen berlen, kömek soranlarynda hiç haçan ýüzüni çytmaýan, elinden gelenini aýamaýan, kiçi göwünli, güler ýüzli we sada adam hökmünde kärdeşleriniň we tanyşs-bilişleriniň ýüreklerinde orun aldy. Her gezek Seýitnazar Ärnazarowy ýatlanymyzda, onuň mähirden doly, biparh garamaýan gözli keşbi hakydamyzda janlanýar. 
